\title{
“Esas madres”. Ser madre en México
}

\author{
Palabras clave: México - madre - estereotipo - imagen lingüística del \\ mundo - Antropología lingüística.
}

\section{Resumen}

El artículo busca reconstruir el estereotipo lingüístico de la madre mexicana. La metodología utilizada es la Etnolingüística y sigue las ideas de la escuela del profesor Jerzy Bartmiński (Universidad de Lublin). La autora analiza los proverbios en español y las expresiones idiomáticas de México, posteriormente se compara la imagen de la madre con entrevistas cualitativas realizadas en México. Las conclusiones muestran la ambigüedad del estereotipo de madre, que, por un lado, merece respeto, pero, por otro, no tiene ningún valor.

\section{Introducción}

El primer objetivo del presente estudio es reconstruir el estereotipo de la madre según los refranes del mundo hispanohablante y de las expresiones o frases hechas usadas en México para compararlo con la imagen reconstruida del habla de las mexicanas. Analizaremos partes de las entrevistas grabadas en Guadalajara en los años 2004-2005 en las que las entrevistadas hablaban de sus madres. El presente estudio se desarrolla dentro del paradigma de la Lingüística antropológica. Adoptamos el método etnolingüístico elaborado por los seguidores del profesor Jerzy Bartmiński de la Escuela Etnolingüística de Lublin para mostrar la riqueza semántica de la palabra.

La palabra "madre" en español (igual que la palabra matka en polaco) significa más que una mujer que ha parido o tiene hijos. Como dice Bartmiński:

Según la intuición de un usuario corriente de la lengua, a la madre le corresponde una característica positiva, acordada socialmente, que incluye no solamente rasgos "esenciales" (es decir, que de la manera obligatoria corresponden a todas las madres y que no pertenecen a las 
que no son madres), sino también los rasgos "típicos", relevantes desde el punto de vista de la comprensión de la semántica de la palabra, de su relación con otras palabras de la lengua y modos de su uso en textos idiomáticos; estos rasgos característicos a nivel de la norma semántica social les corresponden a todas las madres "verdaderas" (al contrario de "madres desnaturalizadas") $)^{1}$.

El conjunto de todas estas características constituye el estereotipo de la madre.

\section{2. "Seas buena madre, que es lo que más vale"}

Vamos a analizar el material paremiológico recogido por Juliana Panizo Rodríguez a base de Más de 21.000 refranes castellanos no contenidos en la copiosa colección del Maestro Gonzalo Correas de Rodríguez Marín (1926); Gran diccionario de refranes de la lengua española: refranes, adagios, proverbios, modismos, locuciones y frases proverbiales recogidos y glosados por el autor de José María Sbarbi y Osasuna (1943); Refranero general ideológico español de Martínez Kleiser (1953). En la larga lista de los refranes recogidos en el artículo "Refranes alusivos al parentesco" podemos observar que un gran número se refiere al amor de la madre, el amor ideal, por ejemplo:

Amor de madre, ni la nieve le hace enfriarse; Amor grande, amor de madre; Amor de madre, que lo demás es aire; Caudal inagotable, cariño de una madre; La amante ama un día, la madre toda la vida; Quien te diga que te quiere más que tu madre, quiere engañarte; Al que no tiene madre no hay que llorarle ${ }^{2}$.

Una no puede ser madre sin tener hijos, por esa razón numerosos refranes se refieren a las relaciones entre ella y su retoño. Lo más importante es su semejanza:

La madre y la hija, por dar y tomar son amigas; Madre e hija visten una camisa; La hija y la madre son como uña y carne; Madre e hija, caben en una camisa, suegra y nuera, ni en toda la pieza; Dos hijas y una madre son tres diablos para un padre ${ }^{3}$.

Por eso, la madre tiene gran influencia sobre sus hijos: "Tal madre, tal hijo pare; La buena madre, cría buena hija; Madre holgazana, cría hija cortesana""4.

1 J. Bartmiński, Językowe podstawy obrazu świata, Lublin, Wydawnictwo UMCS, 2009, p. 154. Todas las traducciones del polaco son de la autora del artículo.

2 J. Panizo Rodríguez, "Refranes alusivos al parentesco", Revista de Folklore, 138, 1992, pp. 205-212, en: Biblioteca Virtual Miguel de Cervantes, <http://www.cervantesvirtual.com/nd/ ark:/59851/bmc2n6w2>, 19 de septiembre de 2020.

3 Ibidem.

4 Ibidem. 
Las relaciones entre una madre y sus hijos son muy íntimas, nadie les entiende tan bien como una madre:

A la hija muda, su madre la entiende; Beso se da al niño, la madre lo recibe en el carillo; Besando al niño, a su madre le hacen un cariño; ¿Quieres ser agradable a la madre del niño? Hazle un cariño ${ }^{5}$.

No obstante, según los refranes los hijos suelen ser ingratos: "Una madre para cien hijos y cien hijos no son para una madre; cuando mi madre está en misa, yo bailo en camisa".

Las paremias hacen resaltar la importancia de la madre:

Casa sin madre, río sin cauce; Madre muerta, casa deshecha; Quien tiene padre, va llorando, quien tiene madre, va cantando; No tener padre ni madre, ni perro que le ladre ${ }^{6}$.

Representan también expectativas que tiene la sociedad respecto a las madres: "El padre para castigar, y la madre para tapar; La buena madre no dice ¿quieres? Sino toma; La buena madre no pregunta ¿quieres? Sino da cuanto tiene; Mujer discreta, madre perfecta”. Es notorio que, según los refranes, las mujeres merecen respeto por el hecho de ser madre: "De mujer que es madre, nadie mal hable; La mujer que es madre, no es mujer, sino ángel". Se la contrapone con frecuencia a la madrastra: "Madrastra, madre áspera; Sé madre a los forasteros, y madrastra a los naturales" .

Podríamos sacar la conclusión igual al refrán: Seas buena madre, que es lo que más vale. El análisis de arriba se basa en un material paremiológico español, suponemos que en gran parte común para todo el mundo hispanohablante, sin embargo, debemos también analizar los refranes mexicanos. El Refranero mexicano de Herón Pérez Martínez menciona solamente cuatro refranes que contienen la palabra madre:

- "Con la madre y con la patria, contra todo y contra todos, con razón y sin ella": la madre y la patria son lo primero y hay que defenderlas a toda costa y como sea.

- "De que la madre es de paso, la hija hasta el cincho azota": se suele aplicar a mujeres para decir que cuando la madre es libertina, la hija siempre irá más allá

- "Madre que consiente, engorda una serpiente": señala el daño que causa una madre cuando al educarlos consiente a sus hijos

- "Chingue a su madre la muerte, mientras la vida nos dure": un refrán popular basado en la exclamación injuriosa "chingue su madre", forma popular del grito "qué chingue a su madre la muerte", que es una invitación a que

5 Ibidem.

6 Ibidem.

7 Para crear una imagen negativa de esta figura basta mencionar las paremias del tipo: Madrastra, el nombre le basta; Madrastra, el diablo la arrastra; Madrastra, reniego de ella y de su casta. 
la muerte fornique con su madre. El refrán significa que se puede insultar a la muerte mientras la vida nos dure ${ }^{8}$.

Resumiendo, según el material paremiológico recogido, el amor de madre es el más grande, es obvio y duradero. La madre debe ser generosa, cariñosa y comprensiva. Su relación con los hijos es íntima, especialmente con hijas que se parecen mucho a su madre. De ella depende cómo serán sus hijos en el futuro, aunque puede resultar que los hijos sean ingratos. En casa ella es la más importante, sin ella "la casa (está) deshecha". Por todas sus cualidades una madre merece respeto. Según Monika Głowicka los refranes "suelen servir de guías, manuales de conducta llenos de consejos", por eso los ejemplos anteriores pueden tratarse de guías para las mujeres. En definitiva, se las aconseja directamente "[ser] buena madre, que es lo que más vale"10. Los refranes mexicanos la igualan la madre a la patria; las dos tienen el máximo valor para los mexicanos y confirman que la influencia de la madre es primordial. Sin embargo, no la recomiendan ser generosa sino severa, ya que consentir a los hijos los echarán a perder. El insulto que contiene uno de los refranes mencionados anteriormente nos lleva a la segunda parte del estudio, a las locuciones idiomáticas que contienen la palabra "madre".

\section{2. "iMe vale madre!"}

Por locución idiomática entendemos un conjunto formal y estabilizado que no tiene una motivación semántica clara para usuarios ${ }^{11}$. Vamos a analizar las locuciones recogidas en tres libros: Diccionario de español usual en México ${ }^{12}$, Diccionario del español en México ${ }^{13}$ y Madre. Perilous Journeys with a Spanish Noun de Liza Bakewell. La lista de locuciones es impresionante. En algunas "madre" significa tener vergüenza, honor (tener o no tener madre); en otros expresa disgusto o expresión molesta "iQué poca madre!". Con frecuencia significa tener muy poco valor o ninguno, no importarle a uno en absoluto "valer algo madre(s)", equivalente a una cosa depreciable: "esas madres". Mientras al gritar "¡A toda madre!" un mexicano quiere decir "iQué

8 H. Pérez Martínez, "Refranero mexicano", en: Academia Mexicana de la Lengua, 2016, $<$ http://www.academia.org.mx/universo:lema/obra:Refranero-mexicano>, 30 de agosto de 2016.

9 M. Głowicka, "Visión de la familia en los refranes españoles", Estudios Hispánicos, XV, Wrocław, 2007, p. 256.

10 Monika Głowicka (op. cit.) cita en su artículo más refranes y seguro que en un artículo no se puede agotar el tema, de ahí que las paremias mencionadas en el presente artículo haya que tratarlas como ejemplos.

11 J. Bartmiński, Językowe podstawy obrazu świata, op. cit., p. 71.

12 L.F. Lara, Diccionario de español usual en México, México, El Colegio de México, 1996, p. 578.

${ }^{13}$ L.F. Lara, Diccionario de español en México, México, El Colegio de México, 2010, pp. 212 214. 
bien!, ¡Qué buena suerte!, ¡De lo mejor!”. Cuando alguien "le da en la madre” o "le parte la madre" a un mexicano, le golpea o derrota ${ }^{14}$.

En el diccionario publicado en 2010 Luis Fernando Lara, su redactor, añadió una lista larga de locuciones utilizadas en la calle mexicana, muchas de ellas malsonantes. El primer grupo de las locuciones se refieren a los insultos más graves como: "chingar alguien a su madre" (mancillarla, violarla); "mentarle la madre a alguien"; "chingar a su madre alguien o algo" (sufrir un daño, estar acabado o muerto); " $i($ La) chingada (puta) madre!" (exclamación que expresa enojo, admiración o sorpresa); "mandar a alguien a chingar su madre" (ningunearlo, deshacerse de él, cortarlo) ${ }^{15}$. De ahí que "echar madres" signifique maldecir, insultar. La madre parece también sustituir una parte del cuerpo: cuando "te das en la madre" resultas herido, golpeado o perjudicado, cuando "te dan en o te parten la madre" significa que estás peleando. Mientras que cuando "estás hasta la madre" estás hasta la coronilla, harto, o muy drogado o borracho. A veces madre significa también una cantidad: "ni madre, pura madre" significa nada, no, de ninguna manera; en cambio "(de) a madre(s)" es en gran cantidad, mucho. Una locución curiosa es "oler/ saber a madre(s)", porque significa oler o saber muy mal ${ }^{16}$.

La lista elaborada por la antropóloga lingüística Liza Bakwell contiene aún más locuciones de nuestro interés. Las locuciones en las que la madre significa equilibrio: "sacar a alguien de madre" (sacar a alguien del quicio); "rayarse la madre" (pasarse). Los derivados relacionados con la violencia: "madrazo, me di un madrazo, le dieron un madrazo, películas de madrazo" (pegar a alguien, golpearlo, golpearse uno contra algo, películas violentas); "madriza" (ser pegado por un grupo de personas); "madreador" (él que pega, un delincuente); "madrearse" (pegar a alguien). Los derivados relacionados con el amor a la madre: "madrero" (que ama a su madre); "mamita, mamacita" (mi cariño, mi amor); "mamitis, sufrir mamitis" (cuando un hombre está apegado a su madre demasiado); y con dar el pecho: "mamarse" (estar borracho); "No mames!" (¡No me digas!). Y finalmente, los derivados con el prefijo des-: "desmadrado" (con resaca); "desmadre" (desorden) ${ }^{17}$.

Resulta difícil sacar conclusiones de este material. Evidentemente falta un estudio etimológico de las locuciones. Sin embargo, intentaremos descubrir lo escondido en la lengua, vivo en la mente de la comunidad. En particular, lo que nos interesa, es el valor emotivo de estas locuciones y derivados. No podemos omitirlo si queremos construir una definición cognitiva, el estereo-

14 L.F. Lara, Diccionario de español usual en México, op. cit., p. 578.

15 Sobre la riqueza semántica de la palabra "chingar" véase J. Tomczak-Boczko, "Czy chingar jest słowem kluczem do meksykańskiej kultury?”, en: Badania nad językiem, tom II, Brudne, odrażajace, niechciane, Poznań, Bogucki Wydawnictwo Naukowe, 2018, pp. 27-40.

16 L.F. Lara, op. cit., pp. 212-214.

17 L. Bakewell, Madre. Perilous Journeys with a Spanish Noun, Alburquerque, University of New Mexico Press, 2012, pp. 75-82. 
tipo $^{18}$. A modo de resumen, en numerosas locuciones "madre" significa algo positivo, lo que más valor tiene para los mexicanos ${ }^{19}$. De ahí que insultar a la madre sea lo más grave. Según Bakewell, todas estas expresiones tienen un punto común: la madre es tu punto débil, es lo íntimo, privado ${ }^{20}$. Los dichos en los que "darse en la madre" significan pelearse, pegar a alguien, dañarse, también podríamos incluirlos en esta categoría de las expresiones en las que "madre" es un punto débil. El valor adjudicado al término podemos deducirlo de las siguientes expresiones: si decimos " $\mathrm{A}$ A toda madre!", queremos decir ¡Qué bien!, mientras que "iQué poca madre!" significa que estamos molestos o disgustados; si tenemos algo de sobra, decimos que lo tenemos "de madre/s". La madre equivale también al honor, vergüenza, pundonor, también al equilibrio y al orden. Si hubiésemos terminado en este momento, podríamos decir que la imagen de la madre derivada de las locuciones es positiva, no obstante, nos queda una lista de expresiones que lo contradicen. En algunas la madre no tiene ningún valor ("ser, valer madre"; "pásame esa madre; ni madre"), en otras equivale a mal olor o sabor. Como hemos podido comprobar, estamos ante una imagen muy ambigua de la madre mexicana: por un lado en el altar de la familia, como la Virgen de Guadalupe, por otro, despreciada.

\title{
3. Opiniones sobre la propia madre
}

\author{
Según Grazyna Habrajska,
}

el análisis de textos es, sobre todo, útil, si investigamos símbolos de ideas, connotaciones lejanas, poco manifestadas por usuarios de la lengua, que con frecuencia están en su subconsciente [...]. El análisis de textos, mejor que otros métodos, refleja una valoración que la lengua tiene en $\mathrm{sí}^{21}$.

A continuación analizaremos partes de entrevistas grabadas en Guadalajara $^{22}$ en las que las mujeres hablaban de sus madres. El tamaño del presente

18 G. Habrajska, "Metody ankietowe i analiza tekstów w badaniach językowego obrazu świata”, en: A. Dąbrowska, J. Anusiewicz (eds.), Językowy obraz świata i kultura, Wrocław, Wydawnictwo Uniwersytetu Wrocławskiego, 2000, p. 81.

19 Para un estudio más escrupuloso sobre los valores que los mexicanos asignan a cada una (y más) de las expresiones mencionadas en el presente trabajo véase el artículo "Matka w języku - definicje i trudności. Przypadek meksykański”, Język w Poznaniu, 8, Poznań, 2017, pp. 151-164.

20 L. Bakewell, op. cit., p. 78.

${ }^{21}$ G. Habrajska, op. cit., pp. 81-82.

22 El trabajo de campo se realizó gracias a la beca de la Secretaría de Asuntos Exteriores del gobierno de México. Tenía carácter cualitativo. Se realizaron 30 entrevistas con hombres y mujeres, habitantes de Guadalajara. La edad de los entrevistados varía de 16 a 75 años. El método usado para la elección de las personas entrevistadas fue el llamado bola de nieve, en el que los entrevistados recomendaban la investigadora a la siguiente persona. Se intentó cuidar la diversidad del origen social de las personas en cuestión, venían de distintos estratos sociales, de los más pobres sin recursos fijos, hasta las familias acomodadas, lo que también garantizaba diferentes niveles 
artículo nos impide adentrarnos en las historias de vida de esas mujeres, en los valores que atribuyen a la maternidad en sí y en otros aspectos del rol de madre. Estos ejemplos tampoco sirven para construir un estereotipo de la madre en México, porque como dice Habrajska, "los textos no son tan buenos para examinar estereotipos y categorizarlos sistemáticamente. El individualismo del autor pone obstáculos en generalizar, pues, el estereotipo es siempre una generalización" 23 . Sin embargo, nos ayudan a entender qué valores se atribuye a las madres, qué se espera de ellas, porque "la lengua es una herramienta de valoración, una fuente de información sobre los valores y un portador de valores" 24 . Con este material de índole antropológica quizás entendamos la confusión lingüística expuesta arriba.

Tras el análisis del material recogido, podemos decir que no hay un modelo de la maternidad. Tenemos, según las entrevistadas, por un lado, madres ausentes, madres trabajadoras, madres que castigan, madres distantes emocionalmente, madres reinas preocupadas por sus asuntos; por otro, madres amigas, madres que aman a sus hijos y que luchan por su futuro, madres abnegadas. Primero, vamos a analizar el lado positivo. Las entrevistadas están agradecidas a sus madres por "sacarles adelante", es decir, proveer de todo lo necesario, en algunos casos comida y mantenimiento, en otros también educación. "Nos dio lo que necesitábamos: comida, vestido, todo, todo [...] todos salieron adelante" (Susana, 45 años). "Cuando me preguntaban a mí a quién más admiro, yo admiro más a mi mamá, porque ella ha sabido sacarnos adelante, ha luchado por nosotros, nos ha dado una vida económica súper bien, o sea, yo estoy estudiando una carrera, nunca me ha faltado nada, ni apoyo económico, ni cariño, ni nada, o sea, siempre mi mamá ha estado allí para ayudarnos" (Paulina, 19 años).

Para varias entrevistadas sus madres son puntos de referencia esenciales, aunque no todas declaran admirarlas. Aunque no en la infancia o en la pubertad, en la edad mayor llegan a entender que son "uña y carne" (Ligia, 63 años). "Me gustaba quedar bien con ella. Cosa que no siempre era posible realmente. Porque muchas cosas yo opinaba diferente, pero prefería que ella pensara que todo era igual" (Diana, 45 años). Las más jóvenes ponen de relieve la relación amistosa que tienen con sus madres: "con mi mamá he tenido comunicación como de amiga a amiga [...]. Yo no trato de echar a mi mamá mentiras grandes" (Paulina 17 años); "A mí se me hace bien padre que mi mamá ha sido como que, o sea, que le preguntas que es el sexo, las drogas, o sea, jamás ha sido que es infarta, te platica abiertamente todo y que experiencias ha tenido y como lo ve" (Sasil, 19 años).

de educación formal. Para los fines del presente estudio se analizarán nueve entrevistas, todas hechas con las mujeres.

${ }^{23}$ G. Habrajska, op. cit., p. 82.

24 J. Bartmiński, Stereotypy mieszkają w języku. Studia etnolingwistyczne, Lublin, Wydawnictwo UMCS, 2009, p. 25. 
Muchas hablan de la rigidez moral de su madre: "Mi mamá era la del castigo y la del sí y la del no, y cuando yo era chica, la de manazos, van que llueven, etcétera" (Ligia). "Ella sabía la línea exacta entre el bien y el mal, no era católica, pero era como muy moral. Así sabía lo que estaba bien hecho y lo que estaba mal hecho" (Diana). Casi todas las entrevistadas hablan de castigos físicos que recibían principalmente de sus madres: "nalgadas" (Lupita, 47 años), "chanclazos" (Susana), "pellizcos" (Diana), "fajazos, manazos" (Ligia), "palizas terribles" (Flor, 32 años). Desde luego, como añaden, sin "dejarles marcas" (Lupita), "sin moretes ni nada" (Flor).

En varias conversaciones se repetía el tema de carencias emocionales y ausencia de la madre. Susana admite que su madre "no nos tenía casi el cuidado porque éramos muchos", no había "una caricia o una palabra de aliento, nunca la hubo, nunca". "Mi mamá trabajaba todo el día, había meses que no la veíamos toda la semana, porque cuando ella llegaba de trabajo, nosotras ya estábamos dormidas, y cuando nosotras íbamos al colegio [...] Yo era la mamá, yo llevaba y traía a mis hermanas a la escuela. [...] Lo único que veíamos era la bolsa de mi mamá puesta en el comedor" (Flor). "Siempre la tuve como si no la hubiera tenido. Sola crecí, yo tenía diez años y ya empezaba a trabajar, aunque mi mamá estuviera con nosotros, ella se preocupaba más, no por estar con nosotros, sino más bien se preocupaba por los gastos de la casa, de que hay que pagar la cuenta, de que hay que arrimar para comer, por esas cositas, no nos daba mucho tiempo a nosotros" (Lupita). Sorprendentemente las madres que trabajaban por necesidad o tenían mucho trabajo a causa de tener muchos hijos, no encuentran compasión y entendimiento de sus hijas.

Ninguna de las entrevistadas idealiza a su madre, sin embargo, todas están de acuerdo con que tienen obligación de cuidarlas en la vejez. "Habemos hijos ingratos que nos dan la vida los padres y que nos cuidan, nos visten, nos dan estudio, cuando pueden, y cuando ya está uno grande, pos, no los visita uno, no los entiende de ya su mayoría de edad, por su vejez, porque todo nos parece mal de que se ponen chiqueados, y sí ¡Ay! y los critica uno. No, yo pienso que debe uno de entenderlos y yo cuando puedo verla, yo voy a verla y diario le hablo por teléfono saber cómo mamá está" (Susana). A pesar de que la madre de Susana había huido del marido violento dejando a los niños con él, ella sigue siendo la figura central para la vida familiar de Susana: cada 15 días los hermanos hacen una reunión con la madre. El hermano de Susana le mantiene a la mamá: "le manda para su renta, le manda para comer, para su teléfono, todo. Nosotros cuando podemos, le ayudamos, pues ya casados. Los hombres sí, le ayudan a mi mamá, le dan su domingo, que la llevan con el doctor, cuando se enferma." (Susana). Igualmente Ligia admite que la relación con su madre había sido difícil, en su vejez también le cuidaba: "Ya luego al revés, ya luego la chiqueaba yo, estaba yo pendiente de ella y todo [...] yo estaba pendiente hasta el último detalle, le llevaba de comer, vivía aquí al lado, entonces le llevaba sus chiqueos que le gustaba, le llevaba «que quiero comprar un estambre», que quiero [...] Todos los días iba yo a visitarla. O sea, cómo te diré, quizás 
debí haber sido más educadita con ella, lo que tu quieras, pero sí, estábamos uña y carne [...] tuve una relación muy cercana, aunque como es lógico nos discutíamos o lo que sea, no sin conflicto" (Ligia). Lupita reprocha a su madre la falta de cariño, no obstante, cuando su madre se quedó sola tras la muerte de su hijo, Lupita le propuso mudarse a su casa. Así llevan 23 años viviendo bajo el mismo techo, Lupita admite que las relaciones entre ella y su madre han cambiado, pero no son fáciles: "a veces salimos de choque [...] pero al rato se le pasa coraje y al rato me viene y me habla y así" (Lupita). En ningún momento Lupita habla del amor que siente por su madre, no obstante, su caso es un ejemplo más de cumplir con la obligación que tienen los hijos hacia la madre.

Debemos recordar que "el grupo de rasgos característicos que el estereotipo incluye no se refiere a todos de una clase, sino a los ejemplares, modelos normales para los que hablan" 25 , de ahí que los fragmentos de las entrevistas analizadas sirvan principalmente para reconstruir las expectativas respecto a la figura de la madre: la intimidad, presencia en la vida de los hijos, cariño, tiempo, asegurar el futuro de los hijos, enseñarles la moral y educarlos castigando. Y tal como ellas tienen obligaciones respecto a sus hijos, ellos en su vejez tienen la obligación de cuidarlas, independientemente del comportamiento de la madre.

\section{Conclusiones}

Vamos a comparar estas expectativas con la imagen dibujada a base del material paremiológico y las locuciones. Según las paremias, la madre verdadera, sobre todo, ama a sus hijos, les da cariño, intimidad, es generosa y benévola, es amiga, especialmente con las hijas. Su papel es primordial en la educación de los hijos, de ella depende si sus hijos serán buenos o malos en el futuro. Sin la madre no funciona la familia, por eso, merece un respeto especial. Estas conclusiones concuerdan con las de Monika Głowicka, que cita a Fernández Pocela, quien opina que "la madre es el personaje femenino más benignamente dibujado y bien tratado por el refranero" 26 . Sin embargo, los refranes mexicanos añaden una cualidad más: la severidad. En cuanto a la importancia, se la iguala a la patria. Cuando analizamos las locuciones mexicanas la imagen de la madre cariñosa y benévola se pone borrosa. Es difícil decir cómo debería ser la madre de acuerdo con estas locuciones, porque la lengua en su desarrollo ya se ha alejado de su primer significado. No obstante, nos interesan los valores atribuidos a la madre: en muchas locuciones la imagen es positiva, por eso insultar a la madre es lo peor que se puede decir a un mexicano. Es el punto débil de los mexicanos, en este sentido también la utilizan en todas las expresiones que se refieren a la violencia. La madre también puede significar

${ }^{25}$ Ibidem, p. 68.

26 M. Głowicka, op. cit., p. 269. 
la cantidad, además de honor, vergüenza, pundonor, equilibrio y orden. Hasta ahora las locuciones comprueban nuestras conclusiones basadas en el material paremiológico, no obstante, en muchas locuciones "madre" no tiene ningún valor, en otras equivale a mal olor o sabor, significa estar harto, muy drogado o borracho. Esta ambigüedad la podíamos comprobar en las entrevistas presentadas. Las entrevistadas hacen hincapié en la importancia que ha tenido o tiene la madre, especialmente en formarles en la moralidad. Al mismo tiempo las critican, cuentan de las carencias que sufrieron en la niñez. No obstante, ninguna niega la obligación que tiene respecto a su madre de cuidarla en la vejez. Porque ser madre en sí conlleva tener valor.

\title{
Referencias bibliográficas
}

\author{
BAKEWELL Liza
}

2012 Madre. Perilous Journeys with a Spanish Noun, Alburquerque, University of New Mexico Press.

BARTMIŃSKI Jerzy

2009a Językowe podstawy obrazu świata, Lublin, Wydawnictwo UMCS.

2009b Stereotypy mieszkaja w języku. Studia etnolingwistyczne, Lublin, Wydawnictwo UMCS. GŁOWICKA Monika

2007 "Visión de la familia en los refranes españoles", Estudios Hispánicos, XV, Wrocław, pp. 265-275.

HABRAJSKA Grażyna

2000 "Metody ankietowe i analiza tekstów w badaniach językowego obrazu świata", en: Dąbrowska A., Anusiewicz J. (eds.), Językowy obraz świata i kultura, Wrocław, Wydawnictwo Uniwersytetu Wrocławskiego, pp. 73-84.

LARA Luis Fernando

1996 Diccionario de español usual en México, México, El Colegio de México.

2010 Diccionario de español en México, México, El Colegio de México.

PÉREZ MARTÍNEZ Herón

2016 "Refranero mexicano", en: Academia Mexicana de la Lengua, <https://www.academia. org.mx/obras/obras-de-consulta-en-linea/refranero-mexicano>, 19 de septiembre de 2020.

PANIZO RODRÍGUEZ Juliana

2016 "Refranes alusivos al parentesco", Revista de Folklore, 138, 1992, pp. 205-212, en: Biblioteca Virtual Miguel de Cervantes, <http://www.cervantesvirtual.com/nd/ark:/59851/ bmc2n6w2>, 19 de septiembre de 2020.

TOMCZAK-BOCZKO Justyna

2017 "Matka w języku - definicje i trudności. Przypadek meksykański”, en: Mikołajczyk B., Taborek J., Woźniak M., Woźnicka M., Zabrocki W. (eds.), Język w Poznaniu, 8, Poznań, Wydawnictwo Rys, pp. 151-164. 


\section{"Esas madres": Being a mother in Mexico}

Keywords: Mexico — mother — stereotype — worldview image — Linguistic anthropology.

\section{Abstract}

The article is an attempt at reconstruction of the linguist stereotype of the Mexican mother. The methodology used is ethnolinguistic and follows the ideas of the Jerzy Bartmiński school (Professor at the University of Lublin). The author analyses Spanish proverbs and idiomatic expressions from Mexico. Subsequently, the image of the mother is compared to the qualitative interviews conducted in Mexico. The conclusions show the ambiguity of the stereotype of a mother who deserves respect, but nevertheless, she has no value.

Fecha de recepción: 12 de noviembre de 2019

Fecha de aceptación: 8 de mayo de 2020 